\title{
ASPECTOS GERAIS PARA A ELABORAÇÃO DO PROJETO ACÚSTICO EM SALAS DE AULA E MÚSICA DO PROJETO GURI
}

\author{
Rayza Tavares dos Santos, Fabrícia Dias da Cunha de Moraes Fernandes Borges \\ Universidade do Oeste Paulista - UNOESTE, Curso de Arquitetura e Urbanismo, Presidente Prudente, SP.
}

\begin{abstract}
RESUMO
A experiência musical envolve todo o corpo humano em seus aspectos físico, emocional e psíquico. Toda essa experiência começa com o ouvir. Mas a boa audibilidade depende de, principalmente, compreensão do que está sendo ouvido, o que é importante para aqueles que estão em processo de aprendizagem musical. o presente trabalho trata de questões acústicas nas salas de aula e música, onde a voz humana e o som instrumental são os objetos das atividades da prática musical nos polos do Projeto Guri. Será apresentado aqui, em linhas gerais, relações entre a arquitetura e acústica e suas aplicações em ambientes pequenos.
\end{abstract}

Palavras-chave: Acústica, Auditório, Música, Projeto Guri, Sala de aula.

\section{GENERAL ASPECTS FOR THE PREPARATION OF THE ACOUSTIC PROJECT IN CLASSROOMS AND MUSIC OF PROJECT GURI}

\begin{abstract}
The musical experience involves the whole human body in its physical, emotional and psychic. All this experience begins with listening. But hearing depends mainly on the understanding of what is being heard, which is important for those who are in the process of musical learning. the present work deals with acoustic questions in classrooms and music, where the human voice and sound are instruments of activities of the musical practice in the poles of the Guri Project. It will be presented here, in general, between architecture and acoustics and their application in small environments.
\end{abstract}

Keywords: Acoustics, Auditorium, Music, Guri Project, Classroom. 


\section{INTRODUÇÃO}

A experiência musical envolve uma gama de estímulos físicos, afetivos e psicológicos, uma vez que a música atua em todos os aspectos humanos. Toda essa experiência atinge o ser humano através da audição e, a partir desse primeiro contato, a música desencadeia uma série de sensações que influenciam o corpo, a mente e as emoções.

De modo geral, o som e a música proporcionam efeitos positivos na vida das pessoas, como pode ser comprovado, por exemplo, nos estudos sobre a musicoterapia, área aplicada ao tratamento de muitas doenças. Mas também podem surtir efeitos negativos, como por exemplo, dores causadas por pressão sonora de alta intensidade, oferecendo riscos para a saúde auditiva. (BRANDÃO, 2016).

No ensino musical, o problema de efeitos negativos são mais relacionados à aspectos de percepção e clareza do som. Muito da ineficiência da aprendizagem musical se deve ao fato de que as salas de aula destinadas ao ensino musical são inadequadas, parcial ou totalmente, por razões que vão desde o espaço físico em si até cada elemento presente no espaço e que influencia, de alguma forma, o fenômeno sonoro.

Esses espaços inadequados podem ser perfeitamente representados pelos polos do Projeto Guri, um programa social que visa o ensino da música para crianças e jovens em situação de vulnerabilidade social do Estado de São Paulo. Esses polos, geralmente, funcionam em residências grandes para, primeiramente, abrigar o programa de necessidades, dividido basicamente em setor pedagógico, que concentra as salas de aula e os espaços de ensaio da orquestra, setor administrativo, que corresponde à coordenação, setor de apoio, que é o conjunto de ambientes de serviço, e recreação, que se refere ao refeitório e espaços de lazer para atividades coletivas e comemorativas.

No entanto, muitas vezes essas residências não oferecem aos usuários do Projeto Guri o pleno exercício de suas atividades, pois a estrutura de uma residência não é preparada para a atividade musical, cujo o som é o principal objeto. Como espaço inadequado para a música, algumas dessas residências acabam tendo problemas estruturais, como ocorreu, por exemplo, em uma das casas onde o polo municipal do Projeto Guri de Mirante do Paranapanema, que apresentou uma fissura extensa e profunda no cômodo onde funcionava as aulas de percussão.

Essa situação de inadequabilidade dos espaços se deve à geometria dos mesmos e à falta de um projeto acústico que ofereça condições para que o som possa ser propagado com qualidade dentro do ambiente. É nesse aspecto que entra a acústica, que estuda o condicionamento dos ambientes que usam o som. (UFMS, 2018).

O presente trabalho objetiva apresentar, em linhas gerais, os aspectos da acústica e sua aplicação em uma situação bem complexa, no que respeita ao projeto acústico: o auditório multiuso. Além das considerações dos autores usados para o embasamento teórico, uma referência projetual que exemplifica um exemplo de auditório multiuso é mostrado para dar mais ênfase à possibilidade de se obter a qualidade acústica em espaços pequenos.

\section{METODOLOGIA}

A metodologia que regeu a elaboração do presente artigo consistiu em estudos de obras teóricas que tratam da acústica voltada para a sua aplicação na arquitetura dos ambientes do programa de necessidades dos polos do Projeto Guri. 


\section{ARQUITETURA E ACÚSTICA}

A superfície é o elemento básico nos edifícios construídos. Esta, associada a formas e materiais, causa influência no comportamento do som e, consequentemente, também no desempenho acústico do ambiente. O som possui alguns comportamentos quando se interage com a superfície, que se assemelham ao comportamento da luz, mas com comprimentos de onda relativamente menores do que esta última. (SOUZA; ALMEIDA; BRAGANÇA, 2016).

Segundo Torres, Ferraro e Soares (2010), entre os fenômenos físicos comuns as ondas sonoras, três são destacadas: a reflexão, a refração e a difração.

A reflexão acontece quando o som atinge um obstáculo e, ao colidir com a barreira, parte ou toda a onda retorna para o meio onde a mesma estava se propagando. Em algumas situações, a reflexão das ondas sonoras podem produzir ecos (som direto seguido de sons refletidos) e reverbações (som direto e refletido acontecendo simultaneamente). (TORRES; FERRARO; SOARES, 2010).

O som direto tende a perder sua intensidade, à medida que a distância percorrida aumenta. Por isso a reflexão, na arquitetura, é usada para reforçar a distribuição sonora e garantir que o som no ambiente seja homogêneo. A intensidade do som também diminui com a absorção sonora dos materiais presentes no meio, pois na reflexão uma parte das ondas retornam para o meio e a outra é absorvida. $O$ índice de absorção sonora de um material é diretamente proporcional à rugosidade do mesmo, ou seja, quando mais poroso ou rugoso o material, maior a sua capacidade de absorção sonora. (SOUZA; ALMEIDA; BRAGANÇA, 2016).

$\mathrm{Na}$ refração de uma onda sonora, ocorre a alteração de sua velocidade, quando esta passa de um meio para o outro, e até pode ocorrer também um desvio de sua direção de propagação. Vale ressaltar que parte da onda sonora, ao ser refratada, é inevitavelmente refletida. (TORRES; FERRARO; SOARES, 2010).

A difração é a capacidade de uma onda contornar obstáculos ou passar por fendas. Nas ondas sonoras a difração ocorre da situação de se ouvir um som emitido do outro lado de uma barreira, mesmo sem ver a fonte sonora que a origina. Isso ocorre porque os grandes comprimentos das ondas sonoras são capazes de contornar grandes obstáculos. (TORRES; FERRARO; SOARES, 2010; SOUZA; ALMEIDA; BRAGANÇA, 2016).

\section{ACÚSTICA DE SALAS}

Ao elaborar um projeto arquitetônico com tratamento acústico, a identificação dos sons que podem interferir é primordial para que a qualidade acústica do ambiente seja boa. Essa identificação é feita por meio de levantamento de dados preliminares ao projeto, como atividades exercidas no local, localização, direção dos ventos, edificações vizinhas, conformação topográfica, entre outros, com um olhar acústico sobre elas. (SOUZA; ALMEIDA; BRAGANÇA, 2016).

A obtenção do máximo de informações para a elaboração de um projeto acústico se dá pela grande dificuldade de se adequar plenamente um ambiente, pois a propagação do som depende de uma grande quantidade de condições para ser bem distribuído. Portanto, a acústica reúne diversos elementos: tamanho da sala, volume, proporção, quantidade e posição dos assentos, materiais, revestimentos, superfície, usuários do ambiente e os acabamentos. (VASCONCELOS, 2002; NEUFERT, 2013).

Neufert (2013) ainda ressalta que as características sonoras dos instrumentos musicais e da voz humana, analisadas individualmente e em conjunto, qualidades e 
características do som e até a forma em que os componentes da orquestra são distribuídos interferem na qualidade do som. $O$ autor ainda deixa claro a importância também de se atentar às relações entre o som direto e o ouvinte, no que respeita às reflexões primarias e tardias.

\section{A ACÚSTICA E O PROJETO GURI}

Entre as atividades relacionadas ao ensino e à prática musical no Projeto Guri, são ministradas aulas de teoria musical, aulas de canto e coral, aulas de instrumento, ensaios com a orquestra e algumas palestras ou aulas gerais com todos os participantes do projeto. Isso significa que, em primeiro lugar, a música é a principal atividade do programa, ainda que a fala também seja presente, mas em casos específicos e, em segundo lugar, para permitir que essas atividades sejam, de fato, consolidadas é necessário o estudo específico de cada tipo de espaço adequado para a prática de tais atividades.

No Projeto Guri, o processo de aprendizagem musical envolve a voz humana falada e a música cantada e/ou tocada por instrumentos. Isso significa que o projeto acústico de uma sala de aula onde a voz e a música são os principais objetos de suas atividades é um processo complexo, pois, além de avaliar as diversas condições dos elementos presentes na sala, esta deverá assegurar a qualidade da palavra falada e da prática da música. (GAIDA, 2012). A tabela 01 mostra como o som deve se comportar nas duas situações.

Tabela 01. Diferenças entre aspectos importantes da acústica em sala de conferência e sala destinada à música.

\begin{tabular}{|c|c|}
\hline SALA DE CONFERÊNCIA & SALA DESTINADA À MÚSICA \\
\hline INTELIGIBILIDADE DA FALA & SOM AGRADÁVEL \\
\hline Baixos níveis de ruído & \multirow{2}{*}{$\begin{array}{l}\text { Boa experiência acústica ao } \\
\text { escutar a música }\end{array}$} \\
\hline Ausência de Ecos & \\
\hline Reverbação reduzida & Reverbação presente \\
\hline
\end{tabular}

Fonte: Bistafa (2005, apud. Gaida, 2012).

Brandão (2016) define esse tipo de ambiente como auditório multiuso. Em linhas gerais, o projeto acústico para uma sala de música e voz, de acordo com autor, requer que:

a) as linhas de visão e acústica entre fonte (não amplificada) e audiência estejam desobstruídas. Isso levará, normalmente, a um palco elevado e a uma plateia inclinada $[. .$.$] ;$

b) em geral, um projeto completo envolve o projeto de um sistema de sonorização. Tal sistema deve ser capaz de reproduzir toda a faixa de frequência dos sinais acústicos usados na sala, de forma que a origem do som seja atribuída à fonte não amplificada (no palco, em geral) e não ao sistema de alto-falantes. [...];

c) quando a música não amplificada for parte importante do programa, deve-se incorporar ao projeto da sala superfícies próximas aos músicos que ofereçam retorno acústico a eles. Isso pode ser feito com refletores posicionados no teto, um projeto adequado do palco ou com a utilização de painéis refletores ou difusores móveis (biombos). [...];

d) o tempo de reverbação da sala [...] deve ser controlado de acordo com o compromisso concordado entre clientes e projetistas. O uso de cadeiras acolchoadas é recomendado, já que ajuda a manter o tempo de reverbação sob controle quando a sala está desocupada ou parcialmente ocupada; 
e) os níveis de ruído de fundo devem ser minimizados e cuidado deve ser tomado com as leis vigentes, a fim de que as atividades realizadas no auditório não provoquem distúrbios nos vizinhos.

Os aspectos gerais supracitados e apresentados por Brandão (2016) podem ser exemplificados pelo Auditorium Del Parco (figura 01), L’Aquila, Itália, projetado por Renzo Piano e Alessandro Traudi. Essa pequena obra se trata de um auditório multiuso, onde apresentações de música, teatro e palestras acontecem.

Figura 01. Auditorium Del Parco, por Renzo Piano e Alessandro Traudi.

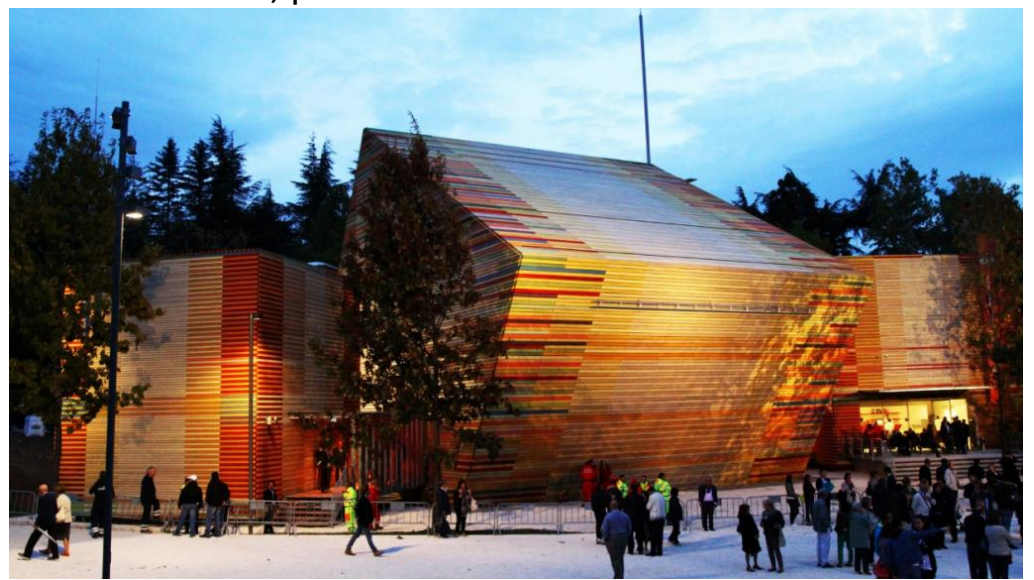

Fonte: RPBW Architects (2013).

Na obra, a inércia do cubo central foi usada na busca pela qualidade acústica das atividades desenvolvidas em seu interior, proporcionando assim que todos os espectadores tenham a visão plena do palco (figura 02).

Figura 02. - Auditorium Del Parco, croqui da inércia do cubo central.

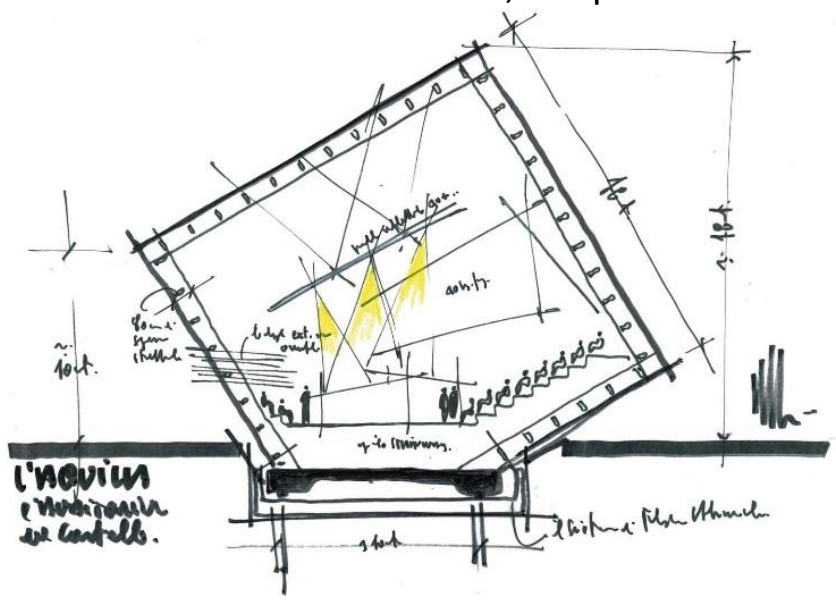

Fonte: RPBW Architects (2013).

Aliado à isso, o auditório conta com elementos importantes para a acústica como a materialidade (em madeira lariço), os painéis refletores, as paredes adjacentes ao palco (figura 03). 
Figura 03. Auditorium Del Parco, interior do auditório e todo seu aparato acústico.

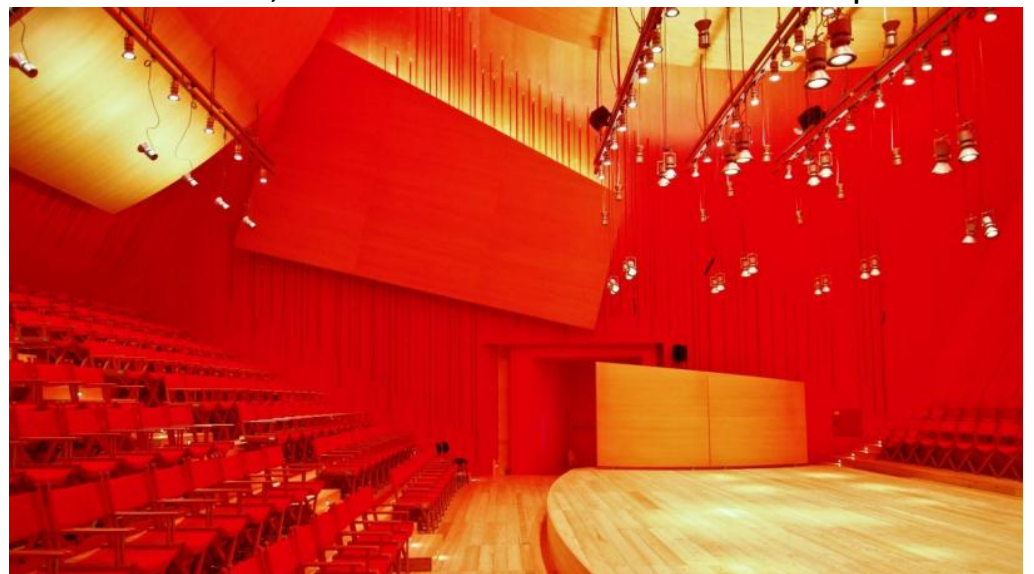

Fonte: B. Barattelli (2016).

\section{CONCLUSÃO}

A acústica como dado de projeto é muito importante em qualquer espaço. Mais ainda em um espaço destinado ao ensino, aprendizagem e prática musical.

Ainda que seja um processo complexo, a boa qualidade acústica influi no sucesso do aprendizado dos alunos de música, na transmissão do som ao espectador e no permitir as atividades que envolvem o som sem a preocupação de estar incomodando os vizinhos.

Apesar da complexidade de projetos acústicos em ambientes que usam da voz humana e do som instrumental, é possível aplicar os requisitos projetuais em espaços pequenos, como os espaços dos polos do Projeto Guri no Estado de São Paulo. Isso pode ser mostrado através do Auditorium Del Parco, onde a questão acústica foi resolvida com eficiência em um espaço pequeno.

\section{REFERÊNCIAS}

BRANDÃO, E. Acústica de salas: projeto e modelagem. 1. ed. São Paulo: Blucher, 2016.

GAIDA, C. R. Caracterização das conduções acústicas de salas de aula destinadas ao ensino de música na educação básica. 2012. 102 f. Dissertação (Mestrado) - Centro de Tecnologia, Programa de Pós-Graduação em Engenharia Civil, Universidade Federal de Santa Maria, Rio Grande do Sul, 2012.

NEUFERT, E. Arte de projetar em arquitetura. Tradução de Benelissa Franco. 18. ed. São Paulo: Gustavo Gili, 2013.

RPBW ARCHITECTS. Auditorium Del Parco. Disponível em: < http://www.rpbw.com/project/auditorium-del-parco>. Acesso em: 09 ago. 2018.

SOUZA, L. C. L.; ALMEIDA, M. G.; BRAGANÇA, L. Bê-á-ba da acústica arquitetônica. 1. ed. São Carlos: EdUFScar, 2016.

TORRES, C. M. A.; FERRARO, N. G.; SOARES, P. A. T. Física - Ciência e Tecnologia: volume 2. 2. ed. São Paulo: Moderna, 2010. 
VASCONCELOS, J. Acústica musical e organologia. 1. ed. Porto Alegre: Movimento, 2002.

UFSM. Universidade Federal de Santa Maria. A Engenharia Acústica. Disponível em: < http://www.eac.ufsm.br/>. Acesso em: 08 ago. 2018. 